\title{
Luc Fraisse, Potocki et l'imaginaire de la création
}

\section{Eric Francalanza}

\section{(2) OpenEdition}

\section{Journals}

\section{Édition électronique}

URL : http://journals.openedition.org/studifrancesi/9250

DOI : 10.4000/studifrancesi.9250

ISSN : 2427-5856

\section{Éditeur}

Rosenberg \& Sellier

\section{Édition imprimée}

Date de publication : 1 juin 2008

Pagination : 198-199

ISSN : 0039-2944

\section{Référence électronique}

Eric Francalanza, «Luc Fraisse, Potocki et l'imaginaire de la création », Studi Francesi [En ligne], 154 (LII | I) | 2008, mis en ligne le 30 novembre 2015, consulté le 13 janvier 2021. URL : http://

journals.openedition.org/studifrancesi/9250 ; DOI : https://doi.org/10.4000/studifrancesi.9250

\section{Ce document a été généré automatiquement le 13 janvier 2021.}

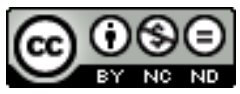

Studi Francesi è distribuita con Licenza Creative Commons Attribuzione - Non commerciale - Non opere derivate 4.0 Internazionale. 


\title{
Luc Fraisse, Potocki et l'imaginaire de la création
}

\author{
Eric Francalanza
}

\section{RÉFÉRENCE}

LUC FRAISSE, Potocki et l'imaginaire de la création, Presses de l'Université Paris-Sorbonne, 2007 («Lettres françaises»), pp. 424.

1 De nombreuses études sont apparues, ces toutes dernières années, sur l'écrivain Jean Potocki (1761-1815), le romancier de Manuscrit trouvé à Saragosse, notamment sa biographie en 2004 et les six volumes de ses œuvres entre 2004 et 2006. On découvre aujourd'hui que ce roman, tout juste terminé au moment où son auteur se donne la mort, édité à Paris en français en 1804, sans l'aveu de l'écrivain, plagié, partiellement publié, traduit en polonais, puis retraduit en français, a connu en fait trois états successifs qui rendent délicate une édition cohérente de l'œuvre. Vu l'importance de l'aura polonaise sur les lettres françaises, il nous apparaît utile de dégager combien ce roman constitue en lui-même une expérience d'écriture parmi d'autres écrits qui, rédigés concomitamment, l'encadrent et l'influencent - ouvrages politiques, journaux de voyage, pièces de théâtre... - et lui confèrent sa problématique identité. L'œuvre se dérobe en même temps qu'elle s'impose comme un roman de la plus belle envergure, tout imprégné des questions de son temps, et pourtant déjà moderne en ce qu'il est, avant Proust ou Borges, un roman du roman. Or cette finalité autoréflexive qui soustend le récit peut faire échapper l'œuvre au romanesque nécessaire à constituer son unité, voire lui faire courir le risque de tourner au non-sens - c'est, au demeurant, une idée qui effleure les biographes de l'écrivain lorsqu'ils considèrent toute l'œuvre.

2 À vrai dire, le roman se fonderait pour sa part non tant sur une absence de sens que sur une absence de centre, hypothèse richement documentée que Luc Fraisse file jusqu'au bout de son livre, mais qu'il commence à développer plus particulièrement dès sa première partie, significativement intitulée «Où est le secret?»: c'est que le secret, qui 
explique le parcours initiatique du héros, exprime le sens symbolique de l'œuvre comme roman du roman. Ainsi se trouvent liés le début et la fin, l'incipit et l'excipit, la première et la dernière partie de l'étude critique. La force mimétique de cette exploration aux confins de l'histoire, de la biographie et de la psychocritique qui entreprend de déceler l'imaginaire de la création chez un auteur déroutant comme Potocki et à travers un roman aussi énigmatique que Manuscrit trouvé à Saragosse, "une pensée et une œuvre qui se construisent sans qu'on puisse en apercevoir le centre», justifie profondément la démarche de Luc Fraisse, laquelle marie avec originalité la méthode historique et l'analyse immanente. C'est qu'il importait de ne pas réduire le sujet à l'étude des seules sources de l'imaginaire, mais de saisir de quelle(s) représentation(s) de la création, de la littérature et du roman, se nourrit l'imaginaire de l'œuvre. La lecture de l'œuvre est du reste postulée par les représentations de la lecture, et même par «une méthode de lecture» ( $2^{\mathrm{e}}$ partie). Elle est quête du lecteur fondée sur une image du livre, voire du Livre - autant dire le Tout que figure non plus la Bible, mais, pour un homme des Lumières comme Potocki, l'Encyclopédie en ce qu'elle relève du mythe d'un réel soumis, voire sublimé par la totalité de l'écriture. Le roman témoigne de ce qui rend impossible cette aspiration à la totalité dans l'ordre des faits ce qui en fait bien une œuvre du tournant des Lumières, quoiqu'elle en nourrisse «l'élan créateur» ( $3^{e}$ partie): le voyage, l'initiation, la peur et la littérature elle-même. Cette autoréflexivité fondée sur l'illusion d'une écriture totalisante requérait alors - et c'est là que la méthode est passionnément opératoire - que, partant d'une conception biographique rénovée de la création, l'étude passât par une lecture de la structure. Tout un intertexte s'explique certes à la lumière de l'existence de Potocki, mais plus encore à partir de l'idée qu'il se faisait de la création. On aurait sans doute pu, dans cette perspective, davantage insister sur les topoï qui refluent des romans antérieurs ou sur ceux qui alimentent l'imaginaire du temps - encore qu'il en soit, et suffisants pour la démonstration, que l'étude interprète avec brio comme les châteaux avec, selon la tradition gothique, leurs prisons et cachots. Mais force est surtout de reconnaître qu'ainsi mise en jeu, la biographie n'est plus confinée dans le détail matériel ou psychologique prétendument significatif, mais étendue à l'ordre d'une structure qui en intègre la substance. C'est, en somme, toute la symbolique de l'œuvre qui se trouve ainsi interprétée, à partir de certains pôles, pas toujours les plus visibles ( $4^{\mathrm{e}}$ partie): le jeu offre, au détour d'une scène, un véritable système d'interprétation de la littérature et de ses finalités. Et peut-être même encore plus subtile est la présence du thèmemotif (on ne sait comment l'appeler) de la maison d'en face, interprétable comme signe historique d'une axiologie littéraire. Ajoutons enfin que la théorisation que produit une étude de ce type ne débouche pas sur un repli de l'enquête sur elle-même: l'auteur appelle de ses vœux une synthèse qui fasse le point sur les sources et la culture de l'écrivain - de nombreux articles ont déjà étayé cette question - ainsi qu'une enquête plus spécifique sur les techniques narratives.

3 Mais le savoureux de ce livre écrit dans un style limpide et orné de quelques belles reproductions (portraits, dessins et documents autographes), c'est encore qu'il nous permet de lire concurremment une enquête minutieuse sur le roman et l'art de Potocki, un discours pour le moins original de la méthode et un essai théorique de la création romanesque et littéraire subtilement inscrit dans l'horizon historique de l'œuvre. 